Research Article

\title{
Experimental Study of Phase Composition of B-Fe-Mn-V Alloys and Thermodynamic Calculations of Phase Equilibria in the B-Mn-V and B-Fe-Mn-V Systems
}

\author{
Viera Homolová $\mathbb{D}^{1},{ }^{1}$ Ján Kepič, ${ }^{1}$ Adéla Zemanová, ${ }^{2}$ and Ondřej Zobač $\mathbb{D}^{2,3}$ \\ ${ }^{1}$ Institute of Materials Research, Slovak Academy of Sciences, Watsonova 47, 04001 Košice, Slovakia \\ ${ }^{2}$ Institute of Physics of Materials, Academy of Sciences of the Czech Republic, Žižkova 22, 61662 Brno, Czech Republic \\ ${ }^{3}$ Department of Inorganic Chemistry-Functional Materials, University of Vienna, Währinger Str. 42, 1090 Vienna, Austria
}

Correspondence should be addressed to Viera Homolová; vhomolova@saske.sk

Received 30 January 2018; Accepted 12 April 2018; Published 24 June 2018

Academic Editor: Pavel Lejcek

Copyright () 2018 Viera Homolová et al. This is an open access article distributed under the Creative Commons Attribution License, which permits unrestricted use, distribution, and reproduction in any medium, provided the original work is properly cited.

\begin{abstract}
Phase compositions of B-Fe-Mn-V alloys were studied by several experimental methods (DTA measurement, X-ray diffractions, and scanning electron microscopy). Besides the experimental study of the quaternary system, thermodynamic modelling of the ternary $\mathrm{B}-\mathrm{Mn}-\mathrm{V}$ system by the Calphad method and thermodynamic calculations for the quaternary B-Fe-Mn-V system were performed. Calculations for the quaternary system are based on the ternary subsystems (B-Mn-V, B-Fe- $\mathrm{V}, \mathrm{B}-\mathrm{Fe}-\mathrm{Mn}$, and Fe-Mn-V). Boron is modelled as an interstitial element in all solid solutions of vanadium, manganese, and iron. Very good agreement between experimental results and thermodynamic calculations was achieved. The created thermodynamic database is suitable for thermodynamic calculations of phase diagrams for all the ternary subsystems and also for the B-Fe-Mn-V quaternary system.
\end{abstract}

\section{Introduction}

The study of the quaternary system B-Fe-Mn-V and its ternary subsystems from the view of phase equilibria is important in several fields of materials research. The systems are the parts of advanced materials for energy industry [1-3]. Boron increases hardenability of steels; vanadium forms stable borides with high melting temperature, hardness, and wear resistance; and manganese improves the strength and toughness of metallic materials. Information about the system is also important for the study of boride coatings on various alloys and metals, including iron [4].

$\mathrm{Up}$ to now, the B-V-Mn system was experimentally studied only by Telegus and Kuzma [5]. They constructed the isothermal section at $1073 \mathrm{~K}$. However, no thermodynamic description of the ternary system was found in their work and also in other literature. Thermodynamic descriptions of the $\mathrm{B}-\mathrm{Fe}-\mathrm{V}$ and $\mathrm{B}-\mathrm{Fe}-\mathrm{Mn}$ systems are given in our previous works $[6,7]$. Neither theoretical nor experimental phase diagram information was found in the literature for the quaternary B-Fe-Mn-V system.

The present work is focused on an experimental study of phase composition of the $\mathrm{B}-\mathrm{Fe}-\mathrm{Mn}-\mathrm{V}$ alloys and thermodynamic calculations of phase equilibria in the B-Fe-Mn-V quaternary system. The thermodynamic calculations are based on ternary subsystems. Therefore, thermodynamic modelling of the ternary B-Mn-V system by the Calphad method was also done in the scope of this work. Besides the study of the B-Fe-Mn-V phase diagram, the aim of this work is the verification of the database based on ternary systems (B-Mn-V, B-Fe-V, B-Fe-Mn, and Fe-Mn-V) for calculations of the quaternary system.

\section{Materials and Methods}

Three quaternary model B-Fe-Mn- $\mathrm{V}$ alloys were produced from high-purity powders of B (99.9\%), Fe (99.98\%), Mn (99.98\%), and V (99.8\%) bought from Alfa Aesar Company 
TABle 1: Chemical composition of alloys and their phase composition after annealing.

\begin{tabular}{lcc}
\hline Alloy & Composition (at \%) & Phase composition at $900 \mathrm{~K}$ \\
\hline 1 & $40 \mathrm{~B}-45 \mathrm{Fe}-5 \mathrm{Mn}-10 \mathrm{~V}$ & $\mathrm{M}_{2} \mathrm{~B}, \mathrm{MB}, \mathrm{V}_{3} \mathrm{~B}_{4}$ \\
2 & $5 \mathrm{~B}-70 \mathrm{Fe}-5 \mathrm{Mn}-20 \mathrm{~V}$ & $\mathrm{BCC}, \sigma, \mathrm{VB}$ \\
3 & $2 \mathrm{~B}-90 \mathrm{Fe}-5 \mathrm{Mn}-3 \mathrm{~V}$ & BCC, $\mathrm{M}_{2} \mathrm{~B}$ \\
\hline
\end{tabular}

(Germany). Powders were mixed and pressed into cylindrical pellets and subsequently melted. The melting was carried out in an argon arc furnace on a water-cooled copper plate in the argon atmosphere of $99.999 \%$ purity. The solidified alloys were remelted several times in order to achieve good homogeneity. The final chemical compositions of the produced alloys $(7 \mathrm{~g})$ are shown in Table 1 . The alloys were then sealed in evacuated silica glass tubes and annealed in the furnace (LAC, Czech Republic) at $900 \mathrm{~K}$ for $2040 \mathrm{~h}$. After the annealing, the samples were quenched into cold water.

The annealed material was studied by X-ray diffraction and scanning electron microscopy JEOL JSM-7000F (JEOL, Japan) equipped with a "thermal FEG" and an INCA EDX analyzer. The backscattered electron image mode of scanning electron microscopy was used to study the alloy microstructure.

For X-ray diffraction, the powder of the samples was prepared by a smooth file and homogenized in a steel mortar. X-ray powder diffraction analyses were performed by a Bruker D8 Advance diffractometer (Bruker, USA) in Bragg-Brentano pseudofocusing geometry, using $\mathrm{Cu}-\mathrm{K} \alpha$ radiation and a LynxEye $^{\circledR}$ one-dimensional silicon strip detector.

Also, DTA (differential thermal analysis) measurements of nonannealed alloy were performed on the apparatus Netzsch DSC 404C (Netzsch, Germany). Pieces of the sample weighing $200-400 \mathrm{mg}$ were sealed in evacuated quartz glass crucibles. Heating and cooling curves were recorded for the sample using a scanning rate of $5 \mathrm{~K} \cdot \mathrm{min}^{-1}$. The DTA instrument was calibrated at the melting points of high-purity In, Sn, Sb, $\mathrm{Zn}, \mathrm{Ag}$, and $\mathrm{Al}$ sealed in quartz crucibles to establish an internal calibration file.

\section{Thermodynamic Model and Calculations}

Thermodynamic calculations of the B-Fe-Mn- $\mathrm{V}$ system were based on data for ternary subsystems. Data for $\mathrm{B}-\mathrm{Fe}-\mathrm{X}$ systems were taken from our previous works. The paper [6] was a source of data for the $\mathrm{B}-\mathrm{Fe}-\mathrm{V}$ system. Data for the B-Fe-Mn system were taken from the literature [7]. Data for the Fe-Mn-V system were taken from the private steel database [8], and the data are shown in Table 2. Data for the last ternary system were not found in any literature, and only one experimental work [5] was found for the B-V-Mn system. The experimental work [5], which described an isothermal section at $1073 \mathrm{~K}$ after annealing for $1200 \mathrm{~h}$, was used for modelling the ternary system. Data for pure elements were taken from the work [9]. For all the calculations, Thermo-Calc software was used [10].
TABle 2: Thermodynamic parameters for the Fe-Mn-V system from the work [8].

\begin{tabular}{lc}
\hline Phase & Parameters \\
\hline$\sigma$ & $G_{0}(\mathrm{Fe}: \mathrm{V}: \mathrm{Mn})=8 \mathrm{GFEFCC}+4 \mathrm{GVBCC}+$ \\
$18 * \mathrm{GHSERMN}-200000$ \\
$G_{0}(\mathrm{Mn}: \mathrm{V}: \mathrm{Fe})=8 \mathrm{GMNFCC}+4 \mathrm{GVBCC}+$ \\
$18 \mathrm{GFEBCC}-150000 ;$ \\
$L_{0}(\mathrm{~V}: \mathrm{Mn}, \mathrm{V})=-100000$ \\
$L_{0}(\mathrm{~V}: \mathrm{FE}, \mathrm{V} ; 0)=-300000$ \\
$L_{0}(\mathrm{Fe}, \mathrm{Mn}: \mathrm{Va})=-7762+3.865 \mathrm{~T}$ \\
$L_{1}(\mathrm{Fe}, \mathrm{Mn}: \mathrm{Va})=-259$ \\
FCC & $L_{0}(\mathrm{Fe}, \mathrm{Mn}: \mathrm{Va})=-2759+1.237 \mathrm{~T}$ \\
& $G(\mathrm{~V}: \mathrm{Va})=\mathrm{GVBCC}+9000$ \\
$\alpha-\mathrm{Mn}$ & $L_{0}(\mathrm{Fe}, \mathrm{Mn}: \mathrm{Va})=-10184$ \\
& $L_{0}(\mathrm{Mn}, \mathrm{V}: \mathrm{Va} ; 0)=-22225$ \\
$\beta(\mathrm{V}: \mathrm{Va})=\mathrm{GVBCC}+10000$ \\
$\beta-\mathrm{Mn}$ & $L_{0}(\mathrm{Fe}, \mathrm{Mn}: \mathrm{Va} ; 0)=-11518+2.819 \mathrm{~T}$ \\
& $L_{0}(\mathrm{Mn}, \mathrm{V}: \mathrm{Va})=-17724$ \\
\end{tabular}

3.1. Thermodynamic Models for Solid Solutions and Liquid. The sublattice model developed by Hillert and Staffansson [11] was used in the present work to describe the Gibbs energy of the individual phases. Boron was considered as an interstitial element.

The Gibbs energies of the BCC, FCC, CBCC, and CUB solid solutions in the system are described using the twosublattice model. Metallic elements occupy the first sublattice, and vacancy $(\mathrm{Va})$ and boron occupy the second (interstitial) sublattice. The Gibbs energy for the twosublattice model $(\mathrm{Fe}, \mathrm{Mn}, \mathrm{V})_{a}(\mathrm{~B}, \mathrm{Va})_{c}$ can be expressed as follows:

$$
\begin{aligned}
G_{\mathrm{SS}}= & \Sigma_{i} y_{i}\left(y_{i} G_{i: \mathrm{B}}^{0}+y_{\mathrm{Va}} G_{i: \mathrm{Va}}^{0}\right)+a R T \Sigma_{i} y_{i} \ln y_{i} \\
& +c R T\left(y_{\mathrm{B}} \ln y_{\mathrm{B}}+y_{\mathrm{Va}} \ln y_{\mathrm{Va}}\right) \\
& +\sum_{i, j} y_{i} y_{j}\left(y_{\mathrm{B}} L_{i, j: \mathrm{B}}+y_{\mathrm{Va}} L_{i, j: \mathrm{Va}}\right) \\
& +y_{\mathrm{B}} y_{\mathrm{Va}} \Sigma_{i} y_{i} L_{i: \mathrm{B}, \mathrm{Va}}+y_{\mathrm{B}} y_{\mathrm{Va}} \Sigma_{i, j} y_{i} y_{j} L_{i, j: \mathrm{B}, \mathrm{Va}} \\
& +y_{\mathrm{Fe}} y_{\mathrm{Mn}} y_{\mathrm{V}} y_{\mathrm{Va}} y_{\mathrm{B}} L_{\mathrm{Fe}, \mathrm{Mn}, \mathrm{V}: \mathrm{B}, \mathrm{Va}}+G_{\mathrm{mag},}, \\
& i, j=\mathrm{Fe}, \mathrm{Mn}, \mathrm{V} .
\end{aligned}
$$

In (1), $y$ represents the site fraction of the component $i$ in the relevant sublattice. The symbols $a$ and $c$ are stoichiometric coefficients of each sublattice (for BCC: $a=1$ and $c=3$; for FCC, СВCC, and CUB: $a=c=1) . G_{i: \mathrm{Va}}^{0}$ is the Gibbs energy of a pure element $i$ in the phase and $G_{i: \mathrm{B}}^{0}$ is the Gibbs energy of a hypothetical nonmagnetic boride, where the element $i$ occupies the first sublattice and all the interstitial positions are occupied by boron.

All values of $G$ are given relative to the standard element reference (SER) state, that is defined as the stable state of the element under standard conditions $\left(298.15 \mathrm{~K}\right.$ and $\left.10^{5} \mathrm{~Pa}\right)$. Interaction parameters $L$ are expressed by the RedlichKister polynomial [12]:

$$
L_{i, j: l}=\sum_{v=0}^{n} L_{i, j: l}^{v}\left(y_{i}-y_{j}\right)^{v}
$$




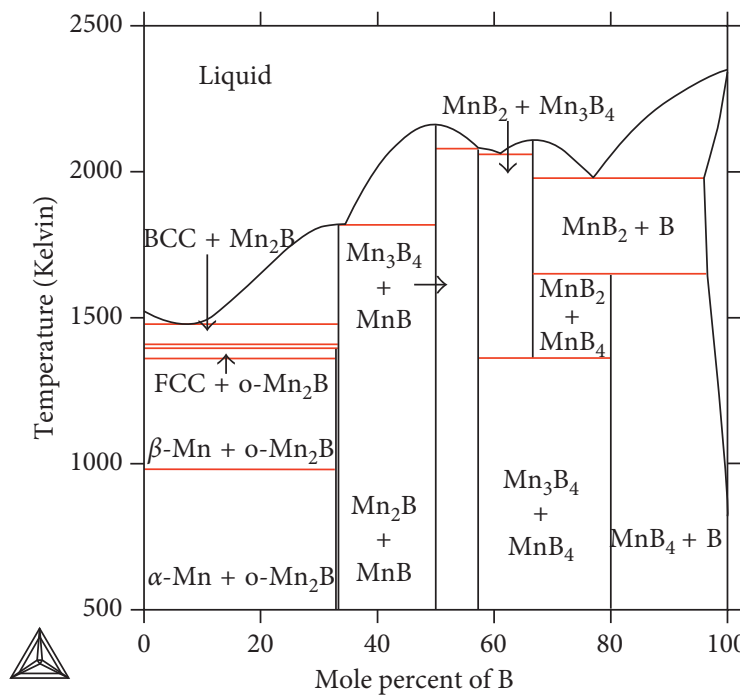

(a)

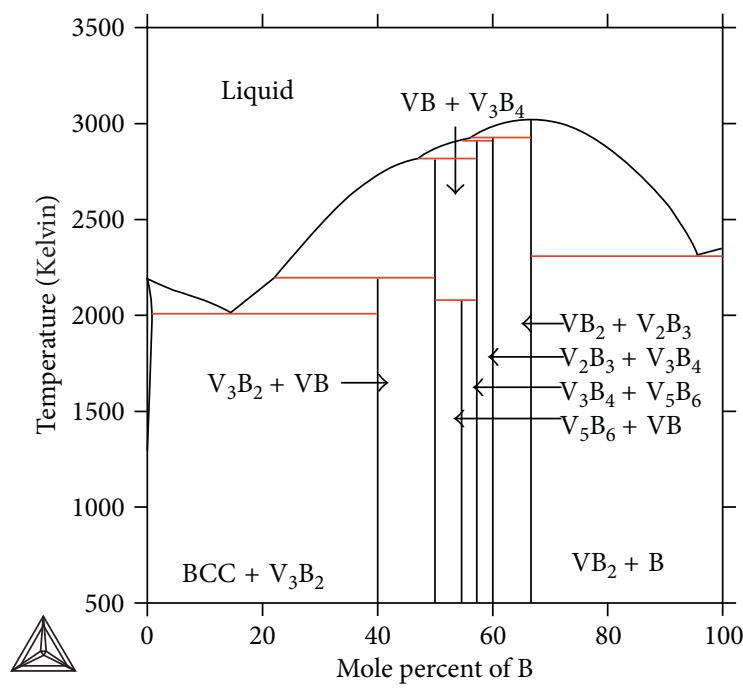

(b)

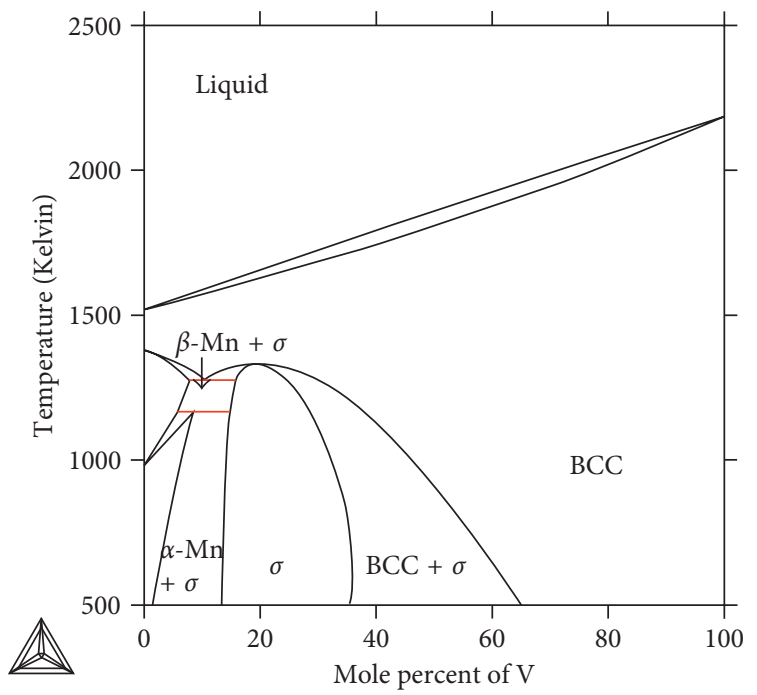

(c)

Figure 1: Phase diagrams of the binary subsystems: (a) B-Mn, (b) B-V, and (c) Mn-V.
TABle 3: Crystallographic data of the phases.

\begin{tabular}{|c|c|c|}
\hline Phase & Pearson symbol/space group & Reference \\
\hline$\delta$-Mn, $\alpha-\mathrm{Fe}, \mathrm{V}(\mathrm{BCC})$ & $c I 2 / \operatorname{Im} 3 m$ & {$[15]$} \\
\hline$\gamma$-Mn, $\gamma$-Fe (FCC) & $c F 4 / F m 3 m$ & [15] \\
\hline$\beta-\mathrm{Mn}(\mathrm{CUB})$ & $c P 20 / P 4_{1} 32$ & [7] \\
\hline$\alpha-\mathrm{Mn}(\mathrm{CBCC})$ & cI58/I43m & {$[7]$} \\
\hline $\mathrm{o}-\mathrm{Mn}_{2} \mathrm{~B}_{0.982}$ & $o F 48 / F d d d$ & [7] \\
\hline$t-\mathrm{Mn}_{2} \mathrm{~B}, \mathrm{Fe}_{2} \mathrm{~B}\left(\mathrm{M}_{2} \mathrm{~B}\right)$ & $t I 12 / I 4 / \mathrm{mcm}$ & [15] \\
\hline $\mathrm{MnB}, \mathrm{FeB}(\mathrm{MB})$ & oP8/Pnma & [15] \\
\hline $\mathrm{Mn}_{3} \mathrm{~B}_{4}$ & $o I 14 / \mathrm{Immm}$ & [7] \\
\hline $\mathrm{MnB}_{2}, \mathrm{VB}_{2}\left(\mathrm{MB}_{2}\right)$ & $h P 3 / P 6 / \mathrm{mmm}$ & [7] \\
\hline $\mathrm{MnB}_{4}$ & $m C 14 / C 2 / m$ & [7] \\
\hline$\beta-\mathrm{B}$ & $h R 108 / R 3 m$ & [7] \\
\hline $\mathrm{V}_{3} \mathrm{~B}_{2}$ & $t P 10 / P 4 / m b m$ & [15] \\
\hline $\mathrm{VB}$ & $o \mathrm{C} 8 / \mathrm{Cmcm}$ & [15] \\
\hline $\mathrm{V}_{5} \mathrm{~B}_{6}$ & oC22/Cmmm & [15] \\
\hline $\mathrm{V}_{3} \mathrm{~B}_{4}$ & $o I 14 / \mathrm{Immm}$ & [15] \\
\hline $\mathrm{V}_{2} \mathrm{~B}_{3}$ & $o \mathrm{C} 8 / \mathrm{Cmcm}$ & [15] \\
\hline$\sigma$ & $c P 2 / P m 3 m$ & [15] \\
\hline$T$ & $t P 10 / P 4 / m b m$ & [16] \\
\hline
\end{tabular}

The interaction parameters $L_{i: l, m}, L_{i, j: l, m}$, and $L_{i, j, k: l, m}$ (where $i, j, k=\mathrm{Fe}, \mathrm{Mn}, \mathrm{V}$ and $l, m=\mathrm{B}$, Va) are defined analogically.

The temperature dependence of the $L^{v}$ parameter is expressed as follows:

$$
L_{i, j: l, m}^{v}=A+B T .
$$

$G_{\text {mag. }}$ in (1) is the magnetic contribution to the Gibbs energy. Its value is calculated according to the model of Hillert and Jarl [13].

The liquid phase is described by a single sublattice. Its Gibbs energy is described as follows:

$$
\begin{array}{r}
G_{\text {Liquid }}=\sum_{i} x_{i} G_{i}^{0}+R T \sum_{i} x_{i} \ln x_{i}+\sum_{i, j} x_{i} x_{j} L_{i, j} \\
+\sum_{i, j, k} x_{i} x_{j} x_{k} L_{i, j, k}+\sum_{i, j, k, l} x_{i} x_{j} x_{k} x_{l} L_{i, j, k, l}, \\
i, j, k, l=\mathrm{B}, \mathrm{Fe}, \mathrm{Mn}, \mathrm{V} .
\end{array}
$$

The $\beta$-rhombohedral $\mathrm{B}$ phase $(\beta \mathrm{B})$ is modelled using one sublattice with the formula $(\mathrm{B}, \mathrm{Mn})$. The following expression described the Gibbs energy of the phase:

$$
G_{\beta \mathrm{B}}=\Sigma_{i} y_{i} G_{i}+R T \Sigma_{i} y_{i} \ln y_{i}+y_{\mathrm{B}} y_{\mathrm{Mn}} L_{\mathrm{B}, \mathrm{Mn}}, \quad i=\mathrm{B}, \mathrm{Mn} .
$$

3.2. Thermodynamic Model for Borides. All borides are described as stoichiometric phases with two sublattices $(\mathrm{Fe}, \mathrm{Mn}, \mathrm{V})_{a}(\mathrm{~B})_{c}$. The Gibbs energy is given as follows:

$$
\begin{aligned}
G_{\mathrm{Borid}}= & \Sigma_{i} y_{i} G_{i: \mathrm{B}}^{0}+a R T \sum_{i} y_{i} \ln y_{i}+c R T \ln 1+y_{i} y_{j} L_{i, j: \mathrm{B}} \\
& +y_{\mathrm{Fe}} y_{\mathrm{Mn}} y_{\mathrm{V}} y_{\mathrm{B}} L_{\mathrm{Fe}, \mathrm{Mn}, \mathrm{V}: \mathrm{B}}, \quad i, j=\mathrm{Fe}, \mathrm{Mn}, \mathrm{V} .
\end{aligned}
$$

3.3. Thermodynamic Model for $\sigma$-Phase. The phase is described with the three-sublattice model with the formula (Fe, Mn)8(V)4 (B, Fe, Mn, V)18. Its Gibbs energy is given as follows: 


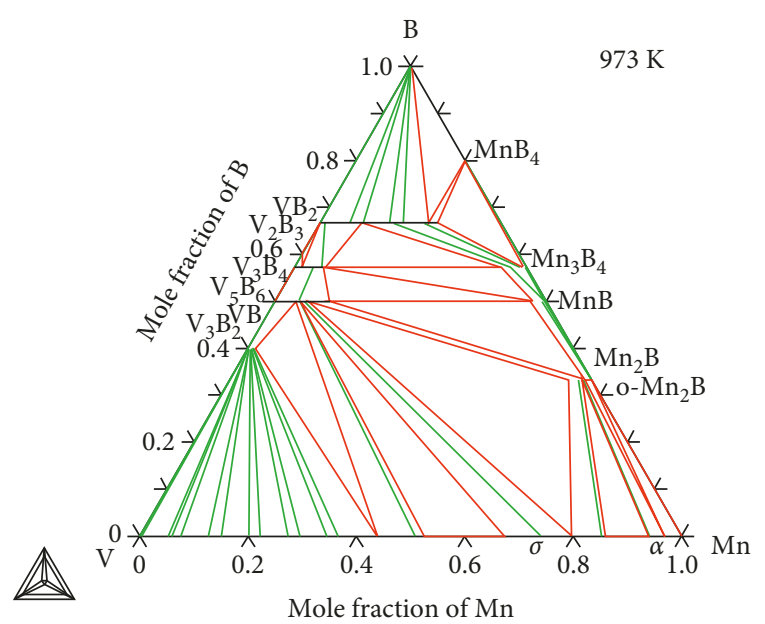

(a)

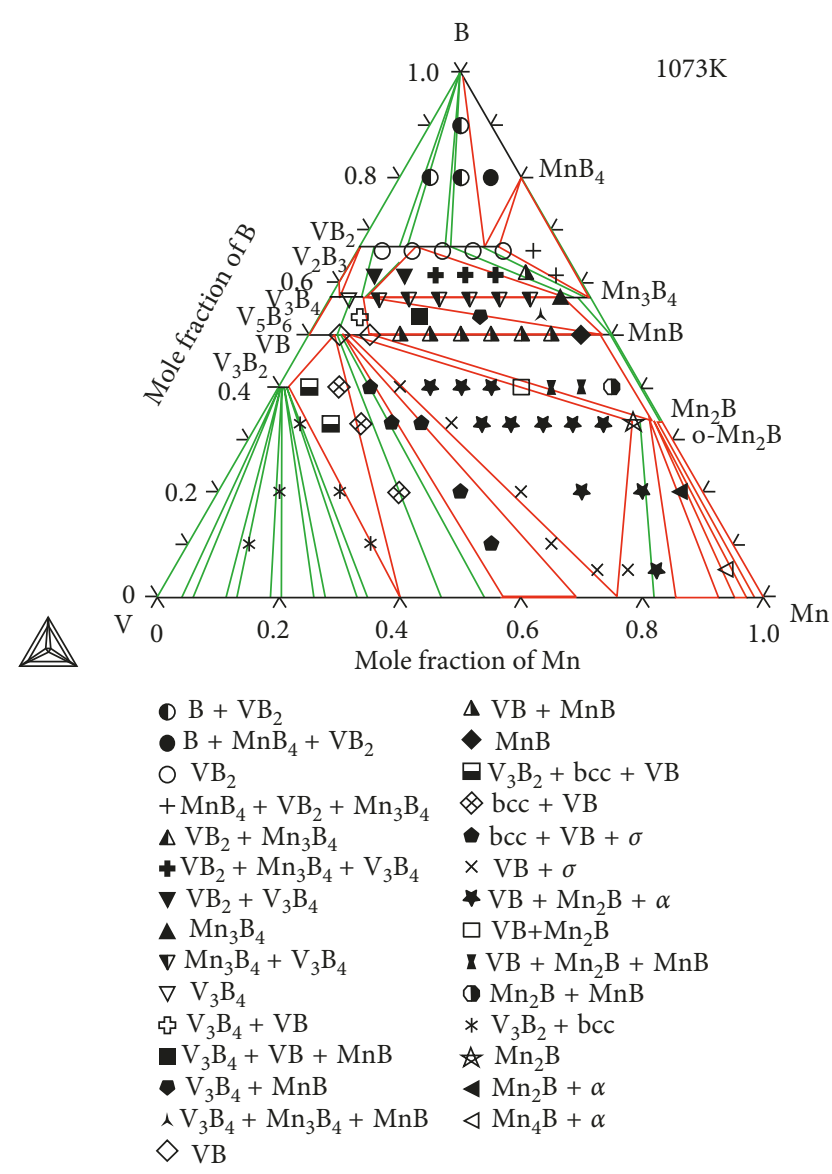

(b)

Figure 2: Continued.

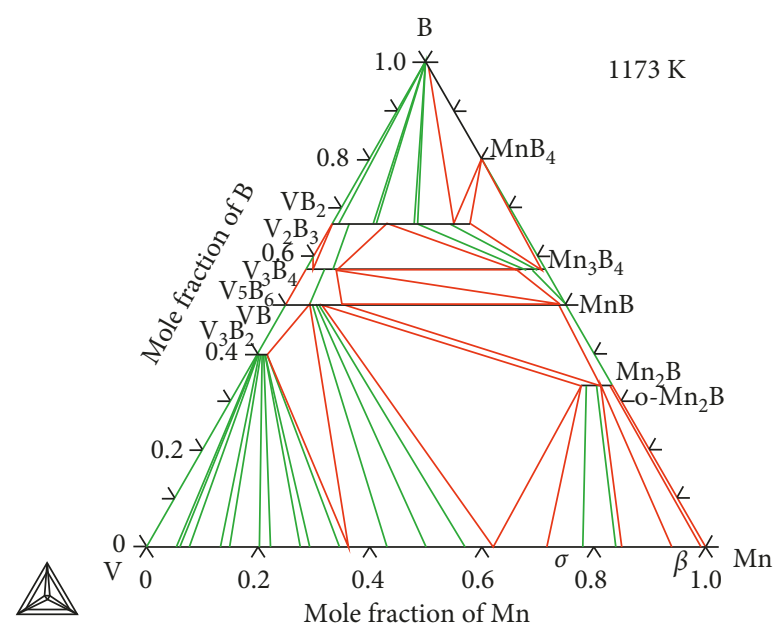

(c)

Figure 2: Calculated isothermal section of the phase diagram of the B-Mn-V system (a) at $973 \mathrm{~K}$, (b) at $1073 \mathrm{~K}$ with experimental data points from literature [5], and (c) at $1173 \mathrm{~K}$.

$$
\begin{aligned}
& G_{\sigma}=\sum_{i} y_{\mathrm{Fe}}^{\mathrm{I}} y_{\mathrm{V}}^{\mathrm{II}} y_{i}^{\mathrm{III}} G_{\mathrm{Fe}: \mathrm{V}: i}^{0}+\sum_{i} y_{\mathrm{Mn}}^{\mathrm{I}} y_{\mathrm{V}}^{\mathrm{II}} y_{i}^{\mathrm{III}} G_{\mathrm{Mn}: \mathrm{V}: i}^{0} \\
& +8 R T \Sigma_{k} y_{k}^{\mathrm{I}} \ln y_{k}^{\mathrm{I}}+4 R T y_{\mathrm{V}}^{\mathrm{II}} \ln y_{\mathrm{V}}^{\mathrm{II}} \\
& +18 R T \Sigma_{i} y_{i}^{\mathrm{III}} \ln y_{i}^{\mathrm{III}}+\Sigma_{k} \Sigma_{i} \Sigma_{j} y_{k}^{\mathrm{I}} y_{\mathrm{V}}^{\mathrm{II}} y_{i}^{\mathrm{III}} y_{\mathrm{j}}^{\mathrm{III}} L_{k: \mathrm{V}: i, j} \\
& +\Sigma_{i} y_{\mathrm{Fe}}^{\mathrm{I}} y_{\mathrm{Mn}}^{\mathrm{I}} y_{\mathrm{V}}^{\mathrm{II}} y_{i}^{\mathrm{III}} L_{\mathrm{Fe}, \mathrm{Mn}: \mathrm{V}: i} \\
& +\Sigma_{i} \Sigma_{j} y_{\mathrm{Fe}}^{\mathrm{I}} y_{\mathrm{Mn}}^{\mathrm{I}} y_{\mathrm{V}}^{\mathrm{II}} y_{i}^{\mathrm{III}} y_{j}^{\mathrm{III}} L_{\mathrm{Fe}, \mathrm{Mn}: \mathrm{V}: i, j} \\
& +\Sigma_{k} \Sigma_{i} \Sigma_{j} \Sigma_{l} y_{k}^{\mathrm{I}} y_{\mathrm{V}}^{\mathrm{II}} y_{i}^{\mathrm{III}} y_{j}^{\mathrm{III}} y_{l}^{\mathrm{III}} L_{k: \mathrm{V}: i, j, l} \\
& +\Sigma_{i} \Sigma_{j} \Sigma_{l} y_{\mathrm{Fe}}^{\mathrm{I}} y_{\mathrm{Mn}}^{\mathrm{I}} y_{\mathrm{V}}^{\mathrm{II}} y_{i}^{\mathrm{III}} y_{j}^{\mathrm{III}} y_{l}^{\mathrm{III}} L_{\mathrm{Fe}, \mathrm{Mn}: \mathrm{V}: i, j, l} \\
& +\Sigma_{k} y_{k}^{\mathrm{I}} y_{\mathrm{V}}^{\mathrm{II}} y_{\mathrm{B}}^{\mathrm{III}} y_{\mathrm{Fe}}^{\mathrm{III}} y_{\mathrm{Mn}}^{\mathrm{III}} y_{\mathrm{V}}^{\mathrm{III}} L_{k: \mathrm{V}}: \mathrm{B}, \mathrm{Fe}, \mathrm{Mn}, \mathrm{V} \\
& +y_{\mathrm{Fe}}^{\mathrm{I}} y_{\mathrm{Mn}}^{\mathrm{I}} y_{\mathrm{V}}^{\mathrm{II}} y_{\mathrm{B}}^{\mathrm{III}} y_{\mathrm{Fe}}^{\mathrm{III}} y_{\mathrm{Mn}}^{\mathrm{III}} y_{\mathrm{V}}^{\mathrm{III}} L_{\mathrm{Fe}, \mathrm{Mn}: \mathrm{V}: \mathrm{B}, \mathrm{Fe}, \mathrm{Mn}, \mathrm{V}} \text {, } \\
& i, j, l=\mathrm{B}, \mathrm{Fe}, \mathrm{Mn}, \mathrm{V} \text { with } i \neq j \neq l, k=\mathrm{Fe}, \mathrm{Mn} \text {, }
\end{aligned}
$$

where numbers I, II, and III denote the sublattice.

\section{Results and Discussion}

4.1. B-Mn-VTernary System. Modelling of the system is based on the same binary data as modelling other ternary subsystems $[6,7]$ of the studied quaternary system and mentioned experimental work [5]. Calculated binary phase diagrams are presented in Figure 1. In the ternary system, liquid, vanadium and manganese solid solutions (BCC, FCC, CBCC, and CUB), intermetallic $\sigma$-phase, $\beta \mathrm{B}$, five vanadium borides $\left(\mathrm{V}_{3} \mathrm{~B}_{2}, \mathrm{VB}\right.$, $\mathrm{V}_{5} \mathrm{~B}_{6}, \mathrm{~V}_{3} \mathrm{~B}_{4}$, and $\left.\mathrm{V}_{2} \mathrm{~B}_{3}\right)$, six manganese borides $\left(\mathrm{MnB}_{4}, \mathrm{MnB}_{2}\right.$, 
TABLE 4: Thermodynamic parameters for the B-Mn-V system developed in the present work.

\begin{tabular}{lr}
\hline Phase & Parameters \\
\hline $\mathrm{M}_{2} \mathrm{~B}$ & $L_{0}(\mathrm{Mn}, \mathrm{V}: \mathrm{B})=-65000$ \\
& $L_{1}(\mathrm{Mn}, \mathrm{V}: \mathrm{B})=-85000$ \\
$\mathrm{MB}$ & $L_{0}(\mathrm{Mn}, \mathrm{V}: \mathrm{B})=-263490+130 \mathrm{~T}$ \\
$\mathrm{~V}_{3} \mathrm{~B}_{2}$ & $L_{0}(\mathrm{Mn}, \mathrm{V}: \mathrm{B})=-186690$ \\
$\mathrm{~V}_{3} \mathrm{~B}_{4}$ & $L_{0}(\mathrm{Mn}, \mathrm{V}: \mathrm{B})=-310000$ \\
& $L_{1}(\mathrm{Mn}, \mathrm{V}: \mathrm{B})=106000$ \\
& $L_{2}(\mathrm{Mn}, \mathrm{V}: \mathrm{B})=180000$ \\
$\mathrm{VB}$ & $L_{0}(\mathrm{Mn}, \mathrm{V}: \mathrm{B})=-128000$ \\
$\mathrm{Mn}_{3} \mathrm{~B}_{4}$ & $L_{0}(\mathrm{Mn}, \mathrm{V}: \mathrm{B})=-500000$ \\
& $L_{1}(\mathrm{Mn}, \mathrm{V}: \mathrm{B})=-5000$ \\
$\mathrm{MB}_{2}$ & $L_{2}(\mathrm{Mn}, \mathrm{V}: \mathrm{B})=-10000$ \\
& $L_{0}(\mathrm{Mn}, \mathrm{V}: \mathrm{B})=-49000$ \\
& $L_{1}(\mathrm{Mn}, \mathrm{V}: \mathrm{B})=-4000$ \\
$\alpha-\mathrm{Mn}$ & $L_{2}(\mathrm{Mn}, \mathrm{V}: \mathrm{B})=13540+12.53 T$ \\
$\beta-\mathrm{Mn}$ & $G_{0}(\mathrm{~V}: \mathrm{B})=\mathrm{GVBCC}+\mathrm{GB} \beta \mathrm{B}+2000$ \\
& $G_{0}(\mathrm{~V}: \mathrm{B})=\mathrm{GVBCC}+\mathrm{GB} \beta \mathrm{B}+2000$ \\
\hline
\end{tabular}

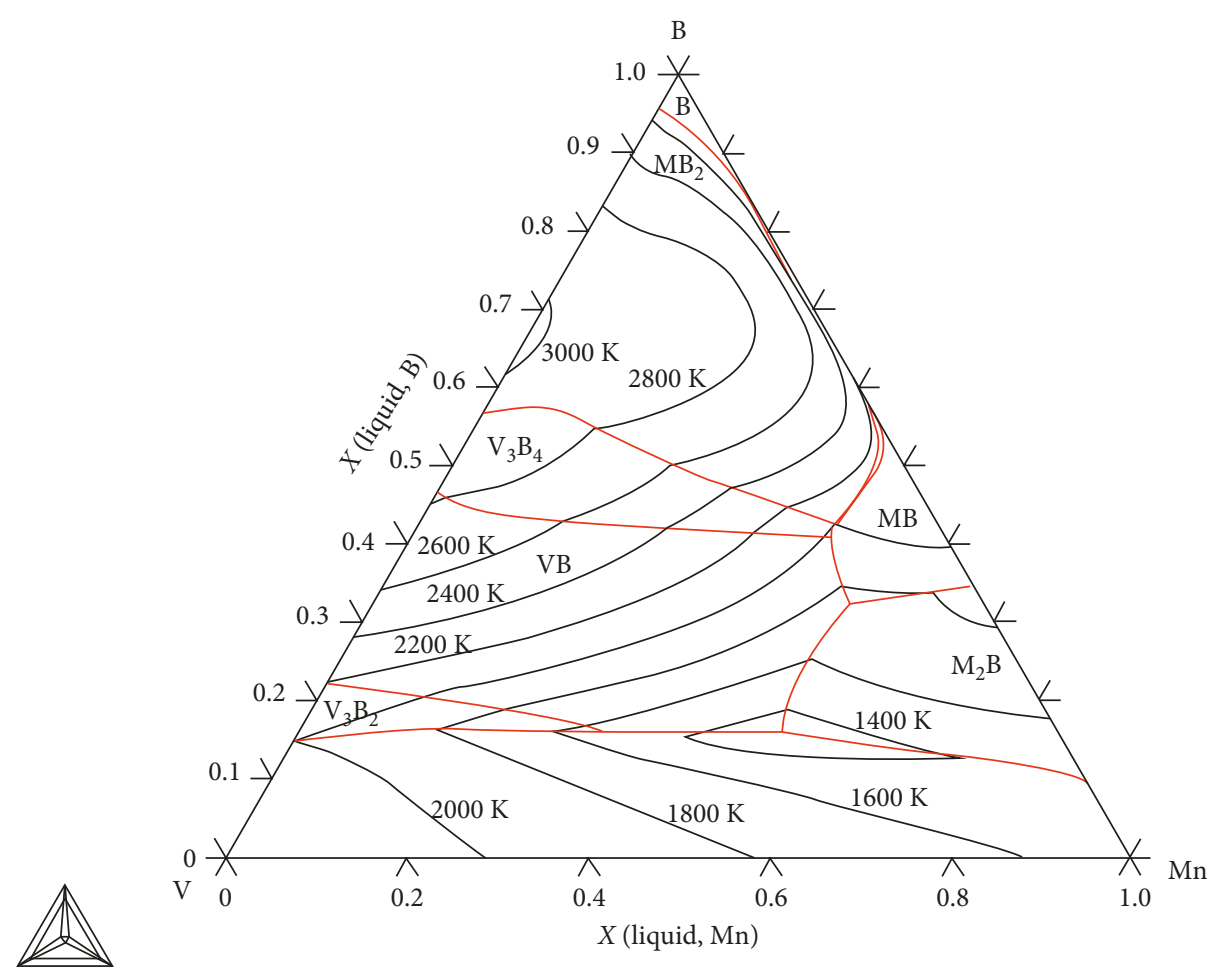

FIGURE 3: Liquidus projection of the B-Mn-V system.

$\mathrm{Mn}_{3} \mathrm{~B}_{4}, \mathrm{MnB}$, and $\mathrm{o}-\mathrm{Mn}_{2} \mathrm{~B}$ ), and $\mathrm{MB}_{2}$ boride were considered. $\mathrm{MB}_{2}$ boride is $\mathrm{VB}_{2}$ phase in the $\mathrm{B}-\mathrm{V}$ system and $\mathrm{MnB}_{2}$ boride in the $\mathrm{B}-\mathrm{Mn}$ system. The $\mathrm{MB}_{2}$ boride is equilibrium phase only for high temperatures in the B-Mn system (Figure 1(a)); however, in the B-V system, it is stable also for low temperatures (Figure 1(b)). No ternary phase was considered in the ternary system, which is conformable with the experimental work [5]. Crystallographic data of the phases are given in Table 3. Calculated isothermal sections at 973, 1073, and $1173 \mathrm{~K}$ are shown in Figure 2. Experimental data points from the work [5] are presented in Figure 2(b). The significant difference between the calculated phase diagram and the work of Telegus et al. [5] is the presence of the o- $\mathrm{Mn}_{2} \mathrm{~B}$ phase in our calculation rather than the $\mathrm{Mn}_{4} \mathrm{~B}$ phase given in the phase work [5]. The decision about the replacement of the $\mathrm{Mn}_{4} \mathrm{~B}$ phase is based on the work of Tergenius [14], who studied the $\mathrm{Mn}_{4} \mathrm{~B}$ phase and redefined the phase as $\mathrm{Mn}_{2} \mathrm{~B}_{0.982}$. Very good agreement between experimental results and the modelled isothermal section at $1073 \mathrm{~K}$ was achieved. Thermodynamic parameters developed in the present work are given in Table 4 . The set of parameters was developed to fit available experimental results at $1073 \mathrm{~K}$ as best as 


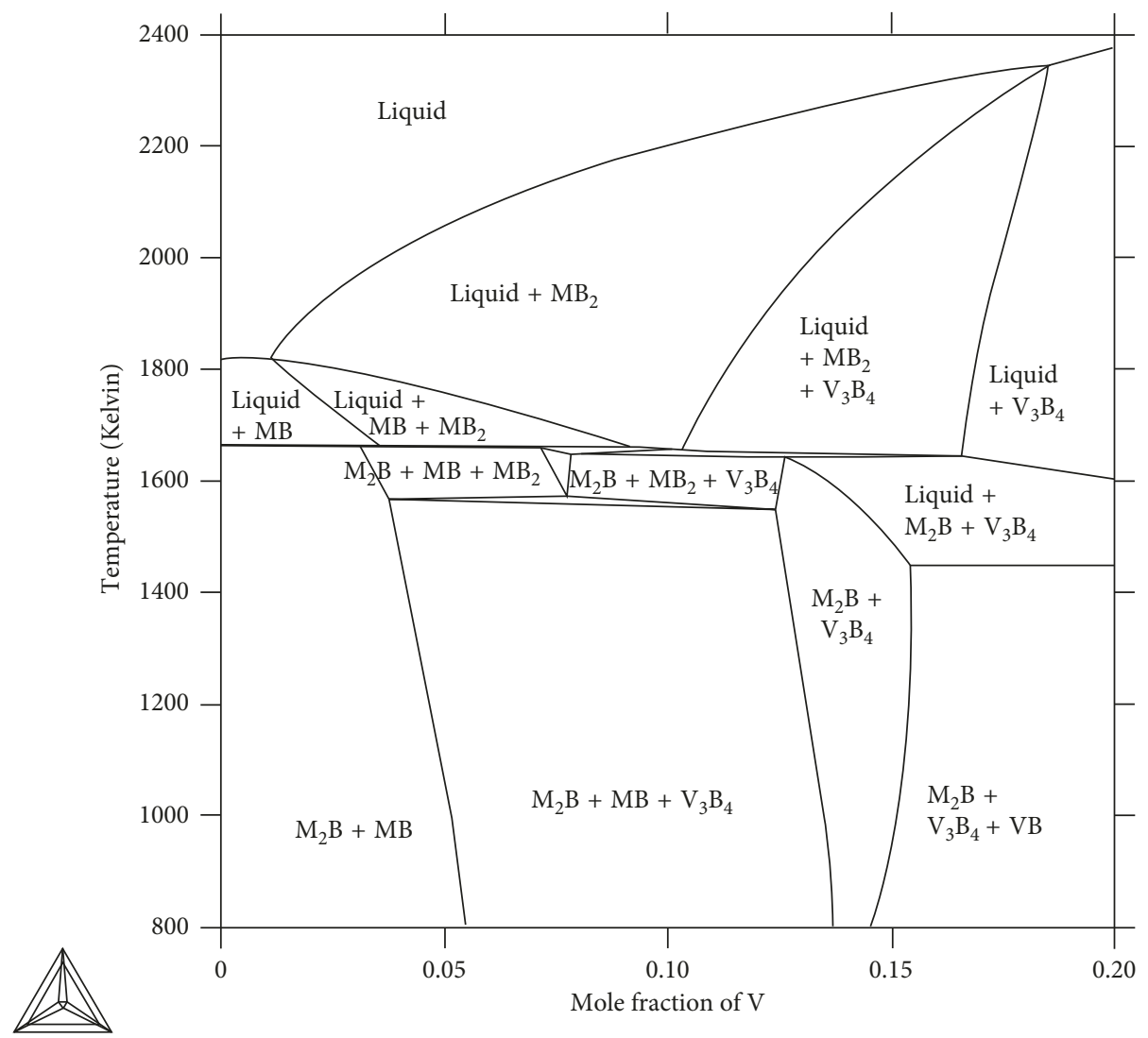

(a)

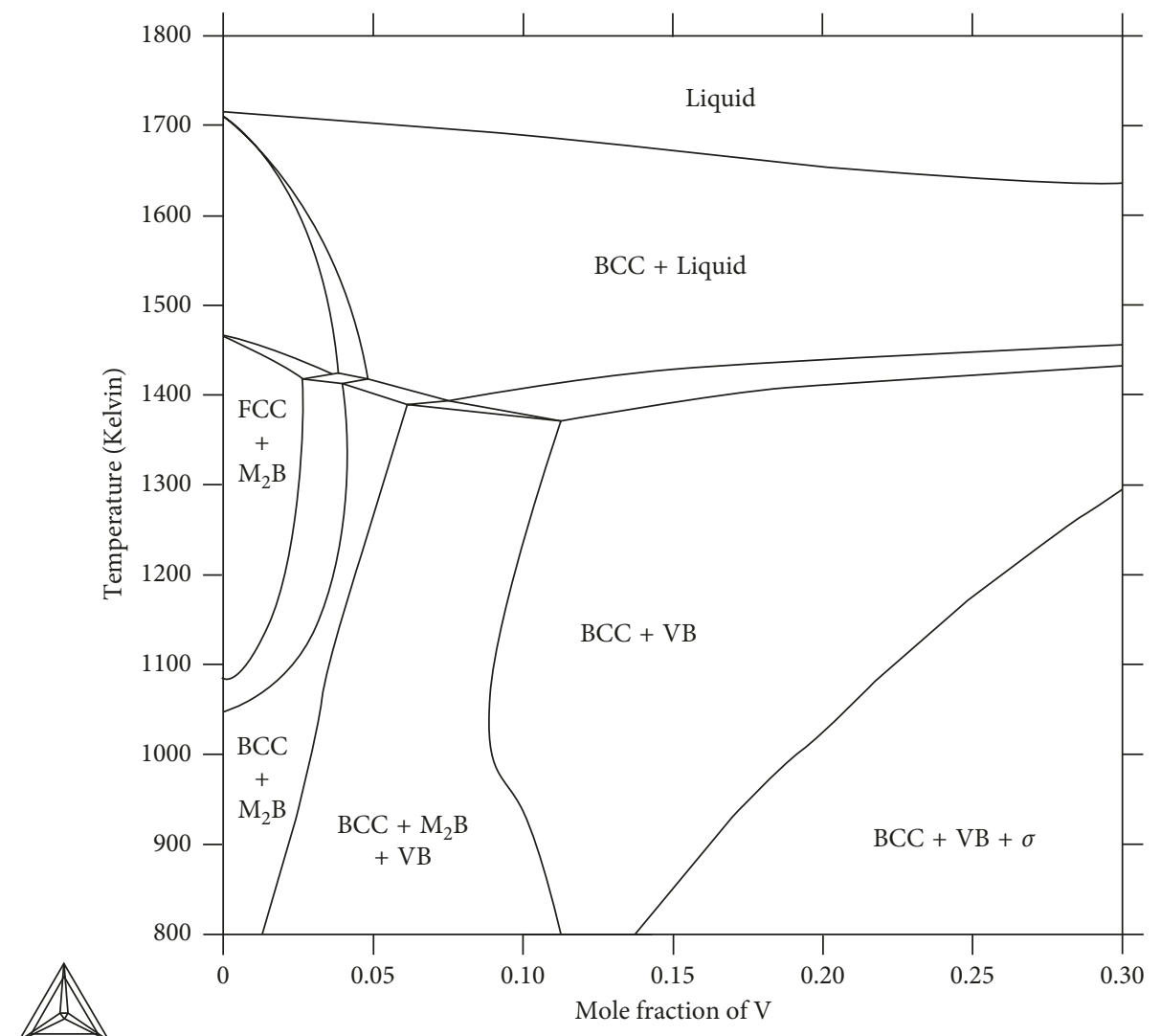

(b)

Figure 4: Isopleth of the phase diagram: (a) 40B-Fe-5Mn-V and (b) 5B-Fe-5Mn-V. 


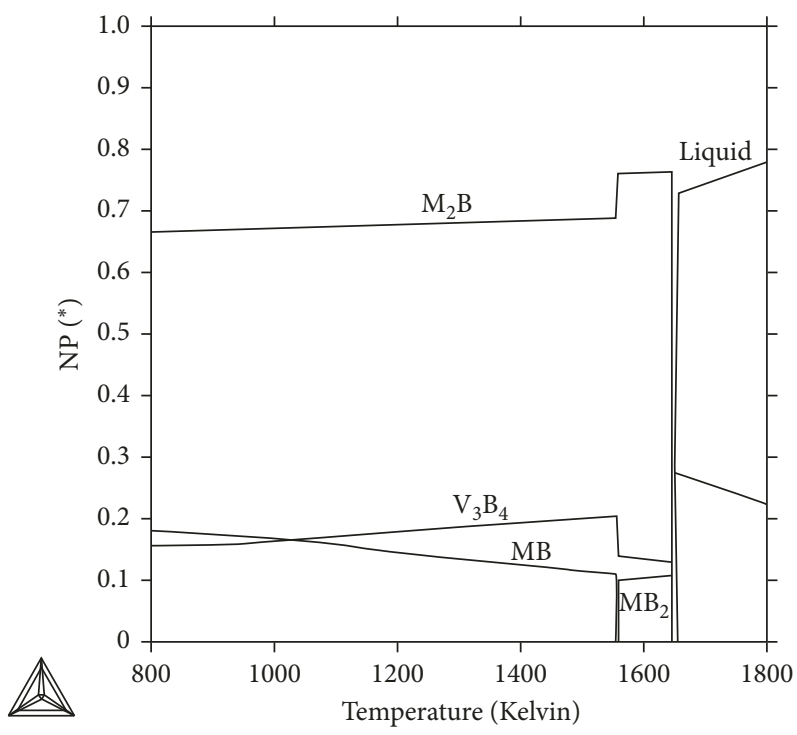

(a)

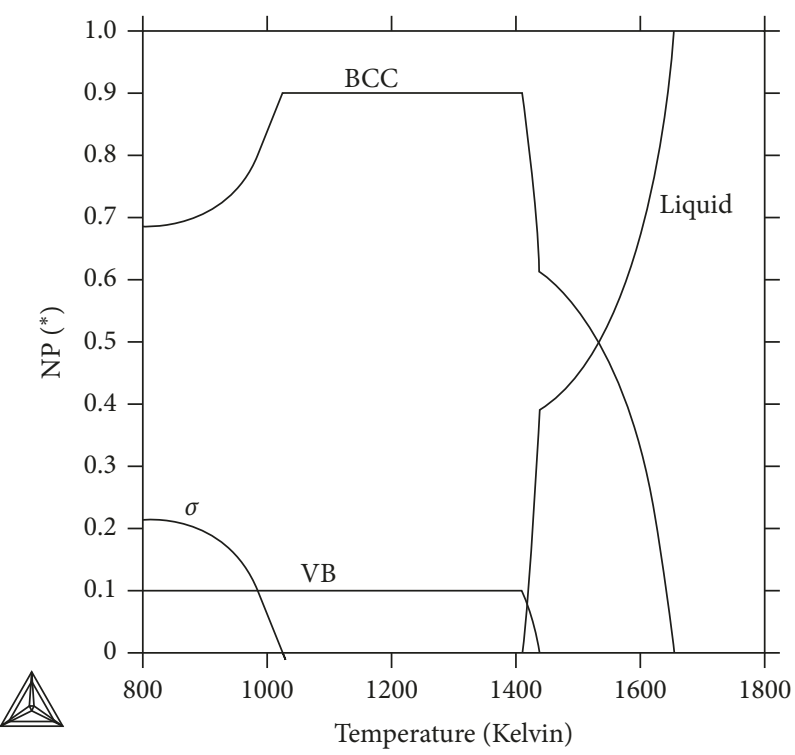

(b)

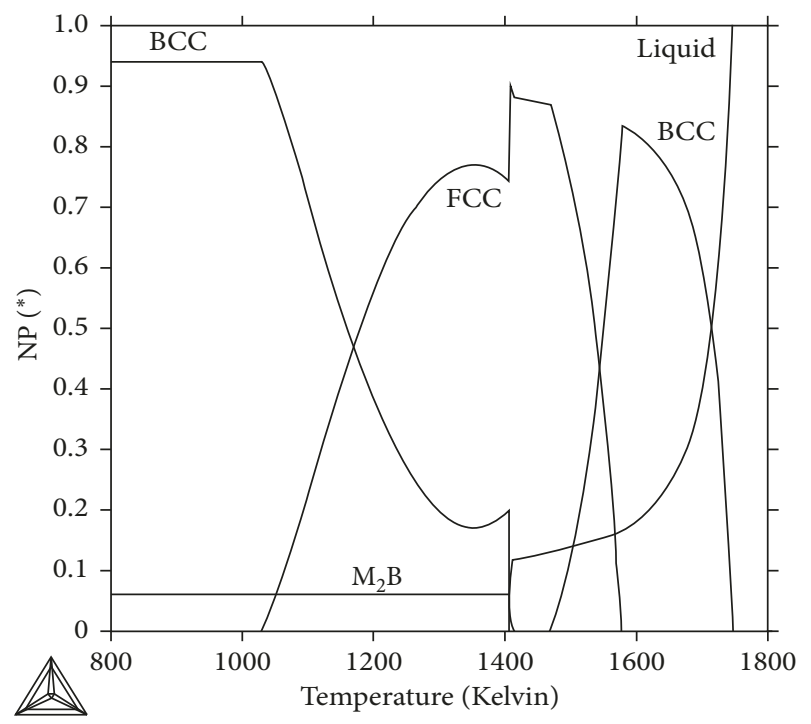

(c)

Figure 5: Calculated phase fractions in dependence on temperature for (a) alloy 1, (b) alloy 2, and (c) alloy 3.

possible and also to calculate reasonable phase equilibria for lower and higher temperatures. Therefore, some parameters are temperature-dependent.

The data were also used to calculate liquidus surface prediction of the system (Figure 3). However, no experimental results about liquidus of the ternary system are known. So, its experimental verification was not possible at this moment.

Considering no other experimental results for the system were found to be better described the B-Mn-V system, the description was used for calculations of a higher system.

4.2. B-Fe-Mn-V Quaternary System. Liquid, several solid solutions of metallic elements, one intermetallic phase, and lot of borides are the equilibrium phases in the quaternary system. Phases identified in the investigated alloys by experimental methods after long-term annealing are given in Table 1. Borides were found in all alloys, the intermetallic $\sigma$-phase was found in alloy 2, and the BCC phase was found in iron-rich alloys.

Calculations of phase equilibria for alloys are presented by isopleths (Figure 4 ) and by mole fractions in dependence on temperature (Figure 5).

Microstructure of the alloy 1 is presented in Figure 6. Large particles of borides are found in the alloy. There are three types of borides: $\mathrm{M}_{2} \mathrm{~B}, \mathrm{MB}$, and $\mathrm{V}_{3} \mathrm{~B}_{4}$. The alloy phase composition is conformable with calculation (Figures 4(a) and 5(a)). Experimentally determined chemical compositions of $\mathrm{M}_{2} \mathrm{~B}(58 \mathrm{Fe}-5 \mathrm{Mn}-3 \mathrm{~V}$ at $\%)$ and $\mathrm{MB}(36 \mathrm{Fe}-9 \mathrm{~V}-5 \mathrm{Mn}$ at \%) borides in the alloy are in very good agreement with the calculated values (Table 5). Experimental values of metallic 

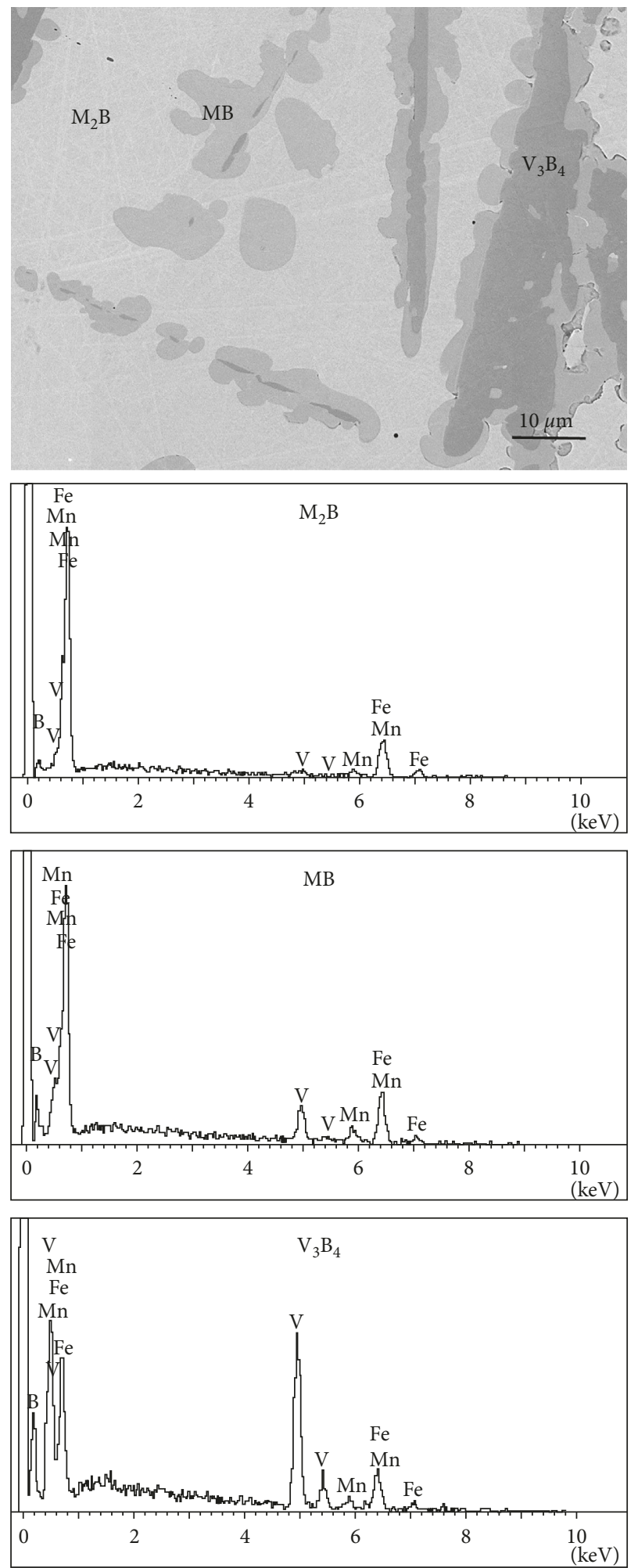

FIGURE 6: Microstructure of the alloy 1 after annealing with the EDX spectrum of identified phases.

elements in $\mathrm{V}_{3} \mathrm{~B}_{4}$ are $29 \mathrm{~V}-2.5 \mathrm{Mn}-11 \mathrm{Fe}$ at \%. There are small differences between experimental and calculated values (Table 5) in the composition of $\mathrm{V}_{3} \mathrm{~B}_{4}$ boride in the alloy.

Alloys 2 and 3 contain significantly less boron than the alloy 1 . Figure 7 shows a eutectic structure of the alloy 2 .

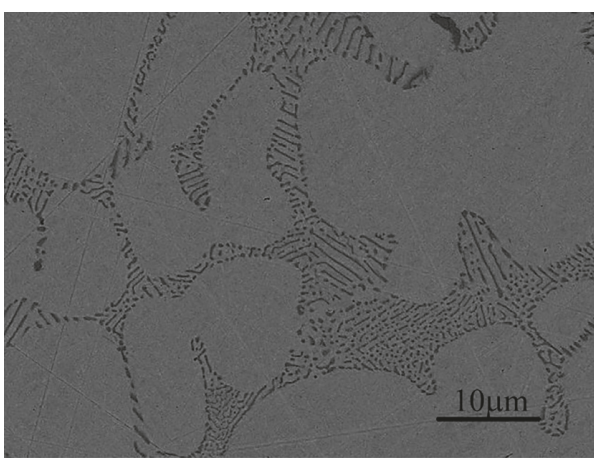

(a)

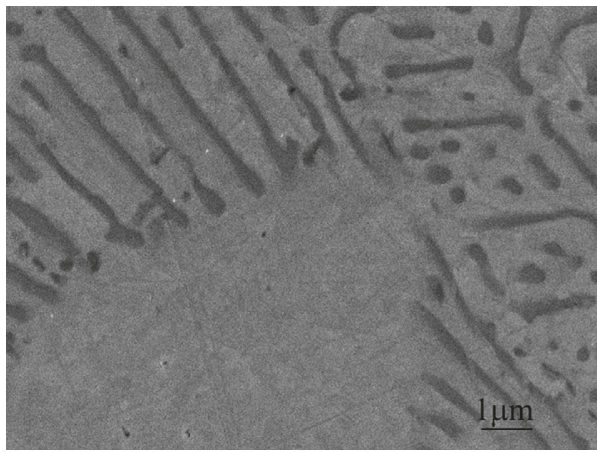

(b)

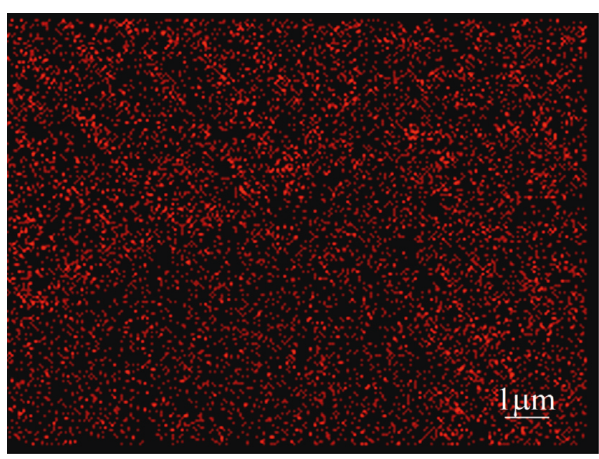

(c)

Figure 7: (a) Microstructure of the alloy 2 after annealing and (b) detail and (c) distribution of vanadium in the corresponding alloy.

TABLE 5: Chemical composition of equilibrium phases at $900 \mathrm{~K}$.

\begin{tabular}{lcc}
\hline Alloy & Phases & Calculated values (at \%) \\
\hline 1 & $\mathrm{M}_{2} \mathrm{~B}$ & $57.3 \mathrm{Fe}-5.2 \mathrm{Mn}-4.1 \mathrm{~V}$ \\
& $\mathrm{MB}$ & $38 \mathrm{Fe}-7.2 \mathrm{~V}-4.8 \mathrm{Mn}$ \\
& $\mathrm{V}_{3} \mathrm{~B}_{4}$ & $38.2 \mathrm{~V}-4.2 \mathrm{Mn}-0.5 \mathrm{Fe}$ \\
2 & $\sigma$ & $63 \mathrm{Fe}-26 \mathrm{~V}-11 \mathrm{Mn}$ \\
& $\mathrm{VB}$ & $44.6 \mathrm{~V}-5.4 \mathrm{Mn}-0.01 \mathrm{Fe}$ \\
3 & $\mathrm{M}_{2} \mathrm{~B}$ & $37.8 \mathrm{Mn}-26.8 \mathrm{Fe}-2 \mathrm{~V}$ \\
\hline
\end{tabular}

The microstructure consists of the matrix and dark particles of borides. The boride particles are too small for exact determination of their chemical composition by EDX. However, the distribution of elements in the alloy (Figure $7(\mathrm{c})$ ) shows that it is vanadium boride. The X-ray diffraction determined the boride as VB. The BCC phase and borides form from liquid. It is in conformance with the calculated 


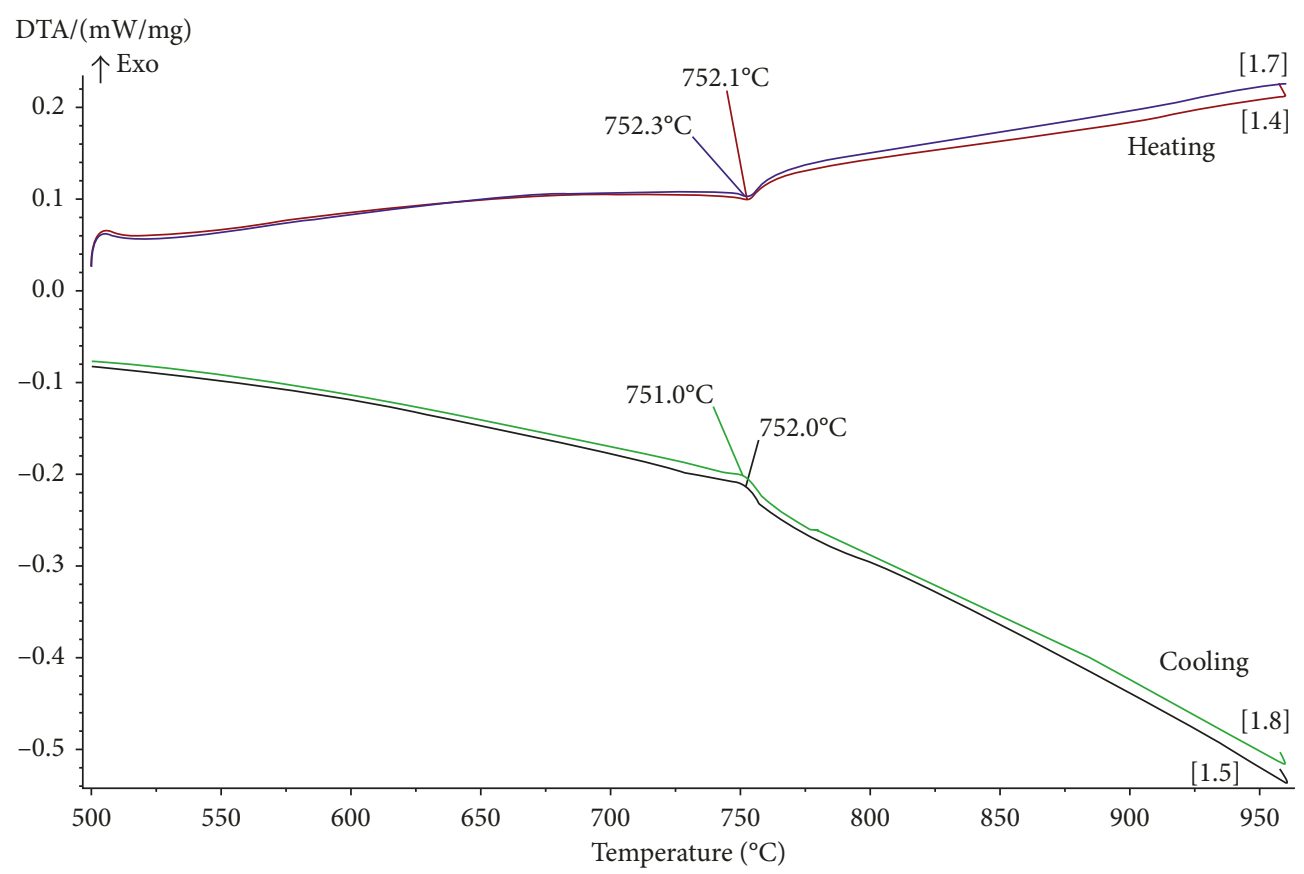

Figure 8: DTA curves (two identical heating and cooling cycles) of alloy 2.

isopleth (Figure 4(b)). The $\sigma$-phase that was determined by $\mathrm{X}$-ray diffraction in the alloy forms as a secondary phase from solid phases. Very similar average atomic numbers of the $\sigma$-phase and matrix do not allow to distinguish between these phases by scanning electron microscopy because the atomic number contrast between them is negligible. It may be a reason why the $\sigma$-phase was not identified by this method. Experimentally identified phase composition of the alloy is in accordance with calculation (Figure 5(b)).

DTA heating and cooling curves of alloy 2 show phase transformation at $1025 \mathrm{~K}\left(752^{\circ} \mathrm{C}\right)$ (Figure 8$)$. The experimentally determined temperature is comparable with the calculated temperature of phase transformation between $\mathrm{BCC}+\sigma+\mathrm{VB}$ and $\mathrm{BCC}+\mathrm{VB}$ (Figure 5(b)). The calculated temperature of the phase transformation is $1024 \mathrm{~K}$. Based on comparison between experimental measurements and calculation, it is supposed that the peak of DTA curves at $1025 \mathrm{~K}$ indicates dissolution of the intermetallic $\sigma$-phase at heating, or formation of the $\sigma$-phase at cooling. There is a very good agreement between experimental measurements and calculation.

The microstructure of the alloy 3 is presented in Figure 9. $\mathrm{M}_{2} \mathrm{~B}$ boride and BCC phase were found in the alloys after annealing. It is in accordance with calculation (Figure 5(c)).

Comparison of experimental and theoretical results shows very good agreement between them. The agreement also indicates that description of the B-Mn- $\mathrm{V}$ ternary system modelled by using a limited number of experimental results is sufficient.

\section{Conclusions}

This work was focused on phase equilibria of the B-V-Mn ternary system and B-Fe-Mn-V quaternary system. The results can be summarized as follows:

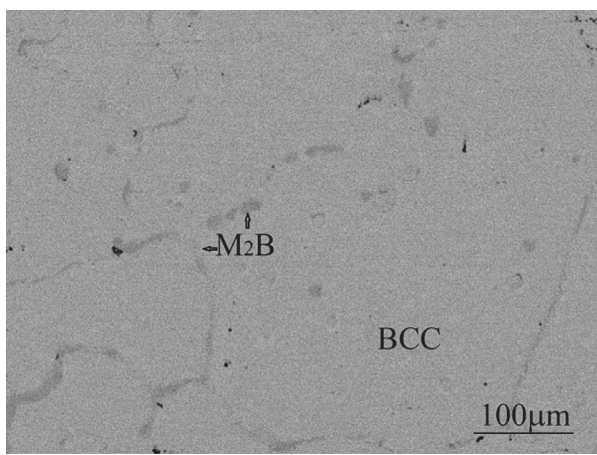

FIGURE 9: Microstructure of the alloy 3 after annealing.

(i) Thermodynamic description of the B-Mn-V system was developed by the Calphad method using available literature experimental-phase data. Boron was modelled as an interstitial element in solid solutions.

(ii) Very good agreement was achieved between experimental results and calculation of the ternary system.

(iii) Extrapolation to the B-Fe-Mn-V quaternary system by using descriptions of all ternary subsystems with no quaternary interaction parameters was done.

(iv) Experimental phase analysis of the quaternary alloys after long-time annealing was performed.

(v) Calculations for the quaternary systems are in very good agreement with the present experimental results.

(vi) Database based on the ternary systems (B-Mn-V, $\mathrm{B}-\mathrm{Fe}-\mathrm{V}, \mathrm{B}-\mathrm{Fe}-\mathrm{Mn}$, and $\mathrm{Fe}-\mathrm{Mn}-\mathrm{V}$ ) is applicable also for calculations of the quaternary system. 


\section{Data Availability}

The data used to support the findings of this study are available from the corresponding author upon request.

\section{Conflicts of Interest}

The authors declare that there are no conflicts of interest regarding the publication of this paper.

\section{Acknowledgments}

The present work was supported by Slovak Grant Agency (VEGA) under Grant no. 2/0073/18. Thanks are also due to Dr. J. Szabó (IMR SAS Kosice) for production of the alloys and Dr. L. Falat (IMR SAS Kosice) for valuable comments.

\section{References}

[1] L. Falat, L. Čiripová, V. Homolová, and A. Kroupa, "The influence of isothermal ageing and subsequent hydrogen charging at room temperature on local mechanical properties and fracture characteristics of martensitic/bainitic weldments for power engineering," Journal of Mining and Metallurgy, Section B: Metallurgy, vol. 53, no. 3, pp. 373-382, 2017.

[2] J. Lu, Y. Song, L. Hua, J. Liu, and Y. Shen, "Influence of thermal deformation conditions on the microstructure and mechanical properties of boron steel," Materials Science and Engineering A, vol. 701, pp. 328-337, 2017.

[3] T. Matsunaga, H. Hongo, and M. Tabuchi, "Interfacial failure in dissimilar weld joint of high boron 9\% chromium steel and nickel-based alloy under high-temperature creep condition," Materials Science and Engineering A, vol. 695, pp. 302-308, 2017.

[4] G. A. Rodriguez-Castro, R. C. Vega-Moron, A. MenesesAmador et al., "Multi-pass scratch test behavior of AISI 316L borided steel," Surface and Coatings Technology, Part: A, vol. 307, pp. 491-499, 2016.

[5] V. S. Telegus and J. B. Kuzma, "Poroskovaja Metalurgija," vol. 97, no. 1, pp. 67-72, 1971.

[6] V. Homolová, A. Kroupa, and A. Výrostková, "Calculation of Fe-B-V ternary phase diagram," Journal of Alloys and Compounds, vol. 520, pp. 30-35, 2012.

[7] P. Repovský, V. Homolová, L. Čiripová, A. Kroupa, and A. Zemanová, "Experimental investigation and thermodynamic modelling of the B-Fe-Mn ternary system," Calphad, vol. 55, no. 2, pp. 252-259, 2016.

[8] A. Kroupa, STEEL16 Database, 2010.

[9] A. T. Dinsdale, "SGTE data for pure elements," Calphad, vol. 15, no. 4, pp. 317-425, 1991.

[10] http://www.thermocalc.com.

[11] M. Hillert and L.-I. Staffansson, "The regular solution model for stoichiometric phases and ionic melts," Acta Chemica Scandinavica, vol. 24, pp. 3618-3626, 1970.

[12] O. Redlich and A. Kister, "Thermodynamics of nonelectrolyte solutions- $x$ - $y$ - $t$ relations in a binary system," Industrial and Engineering Chemistry, vol. 40, no. 2, pp. 341-345, 1948.

[13] M. Hillert and M. Jarl, "A model for alloying in ferromagnetic metals," Calphad, vol. 2, no. 3, pp. 227-238, 1978.

[14] L.E. Tergenius, "Refinement of the crystal structure of orthorhombic $\mathrm{Mn}_{2} \mathrm{~B}$ (formerly denoted $\mathrm{Mn}_{4} \mathrm{~B}$ ), Journal of the Less Common Metals, vol. 82, pp. 335-340, 1981.
[15] P. Villars, Pearson's Handbook, The Materials Information Society, Materials Park, OH, USA, 1997.

[16] P. Rogl, V. Romaka, J. Bursik et al., "Structure and properties of a novel boride $\left(\mathrm{V}_{0.92} \mathrm{Fe}_{0.08}\right)_{2} \mathrm{FeB}_{2}$ with partially ordered $\mathrm{U}_{3} \mathrm{Si}_{2}$-type," Journal of alloys and Compounds, vol. 746, pp. 638-647, 2018. 


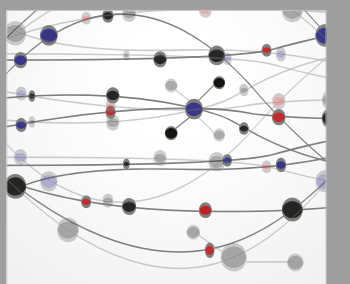

The Scientific World Journal
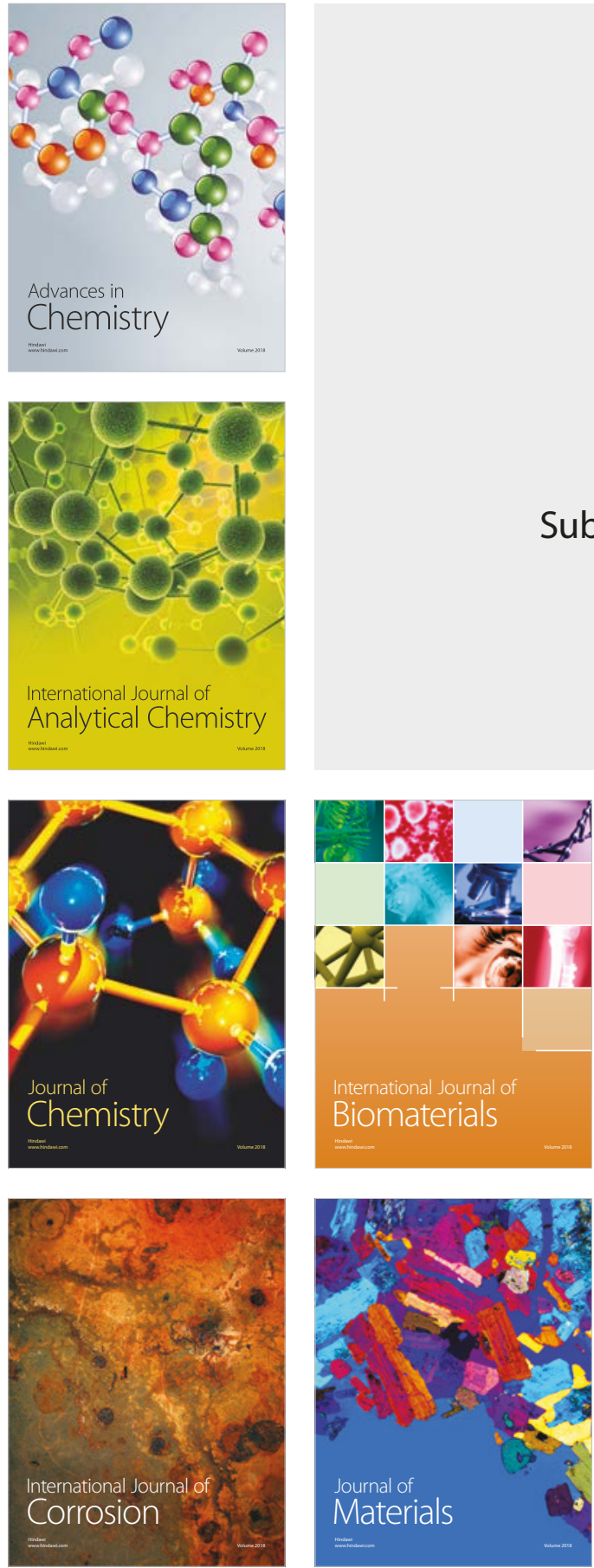

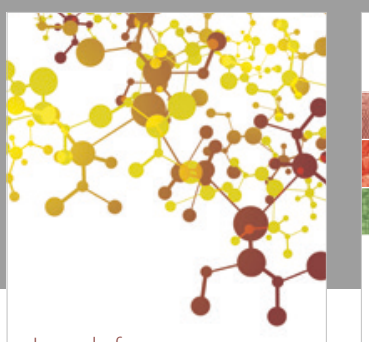

Journal of

Applied Chemistry
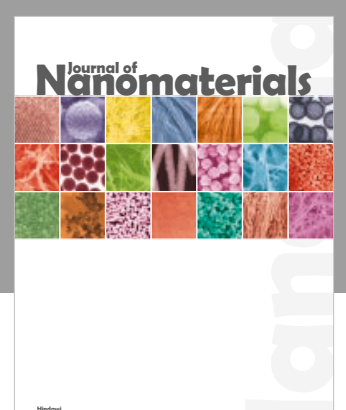

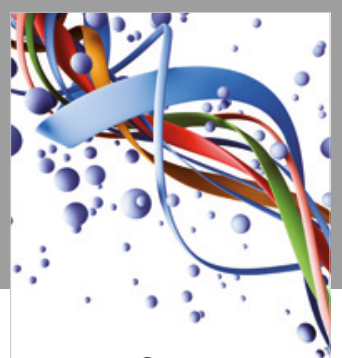

Scientifica

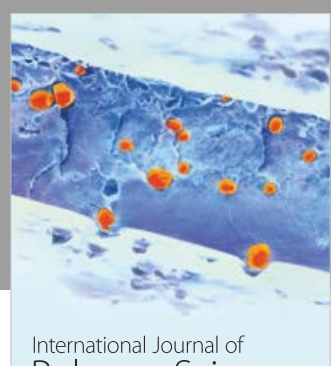

Polymer Science

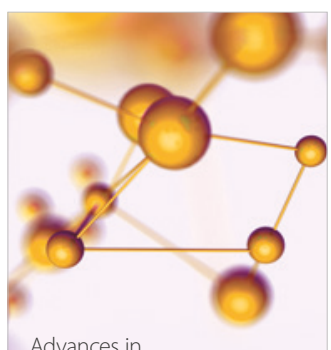

Physical Chemistry
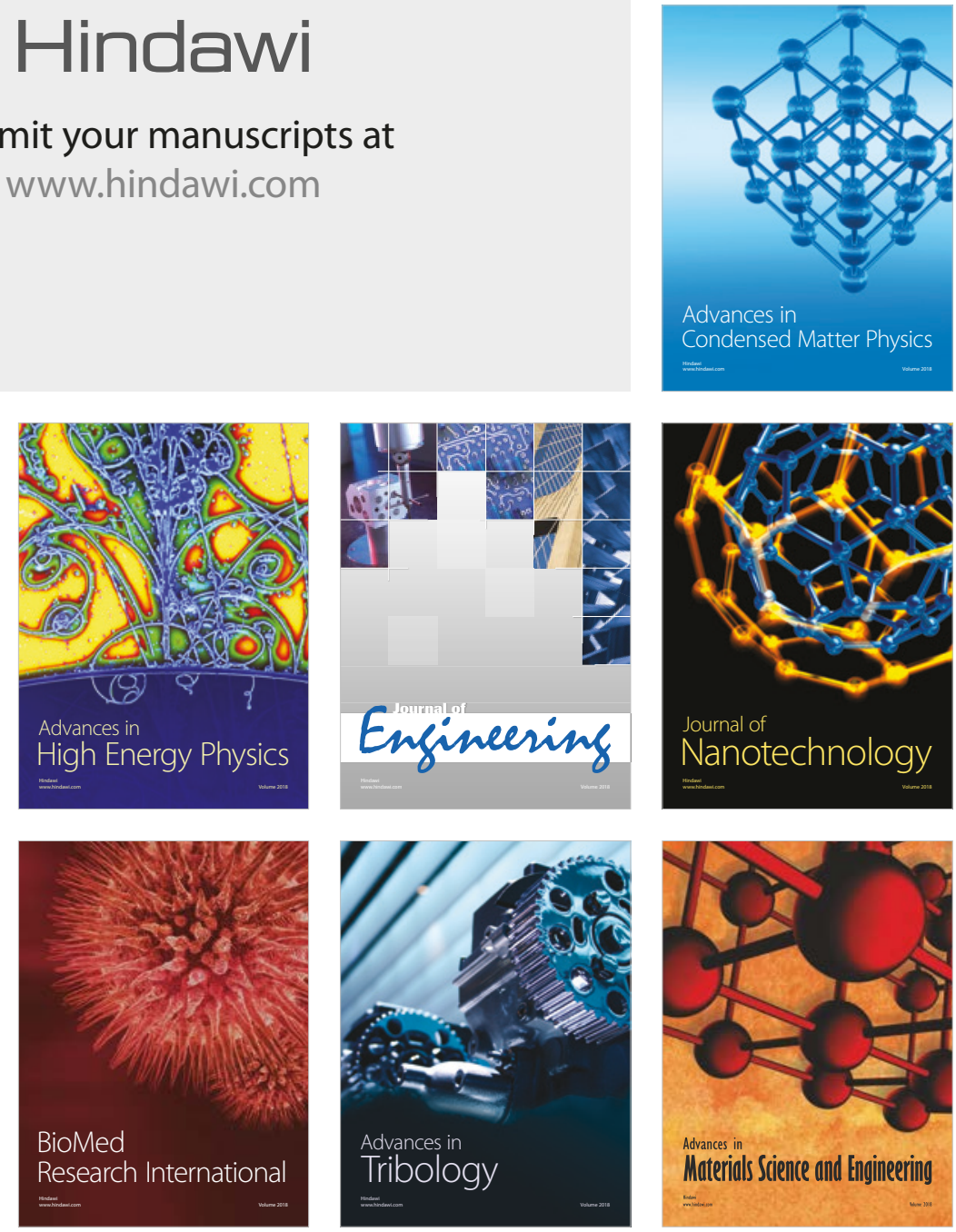